\title{
Spatial and Temporal Variability of Annual Precipitation during 1958-2007 in Loess Plateau, China
}

\author{
Rui Guo, Fengmin Li, Wenying He, Sen Yang, and Guojun Sun* \\ Ministry of Education Key Laboratory of Arid and Grassland Ecology, \\ Lanzhou University, China 730000 \\ sungj@lzu.edu.cn
}

\begin{abstract}
The non-parametric Mann-Kendall method and Sliding $t$-test were applied in this study to analyze the spatial and temporal patterns of trends of the precipitation in the Loess Plateau from 1958 to 2007. The main trends of the precipitation in this region is downward, only four upward time series have not reach the significant level. Most of the abrupt changes happened in northeast of Loess Plateau during 1980s and 1990s. Furthermore, the abrupt changes happened in the northeast portion of the Loess Plateau were relatively later than those in the west portion of the Loess Plateau.
\end{abstract}

Keywords: Trend analysis, Abrupt change, Mann-Kendall method, Sliding $t$-test method.

\section{Introduction}

Loess Plateau is located in arid and semi-arid area of China. It faces too many problems such as low vegetation cover, water scarcity and severe soil erosion and so on. Lots of the problems were affected by the precipitation. The precipitation is also one of the major factors limited agricultural and forestry productivity. Fierce human activities increase the possibility of abrupt changes in climate[1]. It is a meaningful work to find out the regulation of the precipitation in Loess Plateau.

Mann-Kendall trend test is a non-parametric, rand-based method for assessing the significance of trends in time-series data such as water quality, streamflow, temperature, and precipitation[2]. Not only can examine the trends in time-series decline or increase, but also reflect the degree of changes, Mann-Kendall trend test could be a very good description of the characteristics of the time-series trend. Now, the Mann-Kendall trend test has been widely used and tested as an effective method to evaluate a presence of a statistically significant trend in hydrological and climatological time series[2-4]. In the study, we use this method to test trends on precipitation in Loess Plateau from 1958 to 2007. The Sliding t-test[5] was used to detect the abrupt changes in the study.

\footnotetext{
Corresponding author.
} 
The objectives of this study are (1) to reveal the spatial and temporal patterns of trends of the precipitation in the Loess Plateau; (2) to analyze the abrupt changes of the precipitation in the Loess Plateau from 1958 to 2007.

\section{Study Area and Data Processing}

\subsection{Loess Plateau}

The Loess Plateau is a subsystem of mutually interlinked and feedback system of northwest Gobi desert, middle Loess plateau and east alluvial plain[6]. It is located in the middle reaches of the Yellow River and extends 7 latitudes $\left(35-41^{\circ} \mathrm{N}\right)$ and 13 longitudes $\left(102-114^{\circ} \mathrm{E}\right)$, with total area of more than $630,000 \mathrm{~km}^{2}$ and a population of 86 million. The plateau area is $1000-1600 \mathrm{~m}$ above sea level and surface is covered by an average 100-meter thickness of loess-paleosol layers. The Loess Plateau belongs to the continental monsoon region with annual average temperature of $4.3^{\circ} \mathrm{C}$ in northwest and $14.3^{\circ} \mathrm{C}$ in southeast. Annual precipitation ranges from $300 \mathrm{~mm}$ in northwest to $700 \mathrm{~mm}$ in southwest[7]. There is much sunshine in the Loess Plateau. The soil erosion rate on the Loess Plateau of China is among the highest in the world. Loess Plateau contains arid and semi-arid regions; the eco-environment is fragile.

\subsection{Precipitation Data}

The precipitation data were downloaded from China Meteorological Data Sharing Service System. The time series of annual precipitation records at 42 meteorological stations were used in this study from 1958 to 2007. The stations in the Loess Plateau were shown in Fig.1.

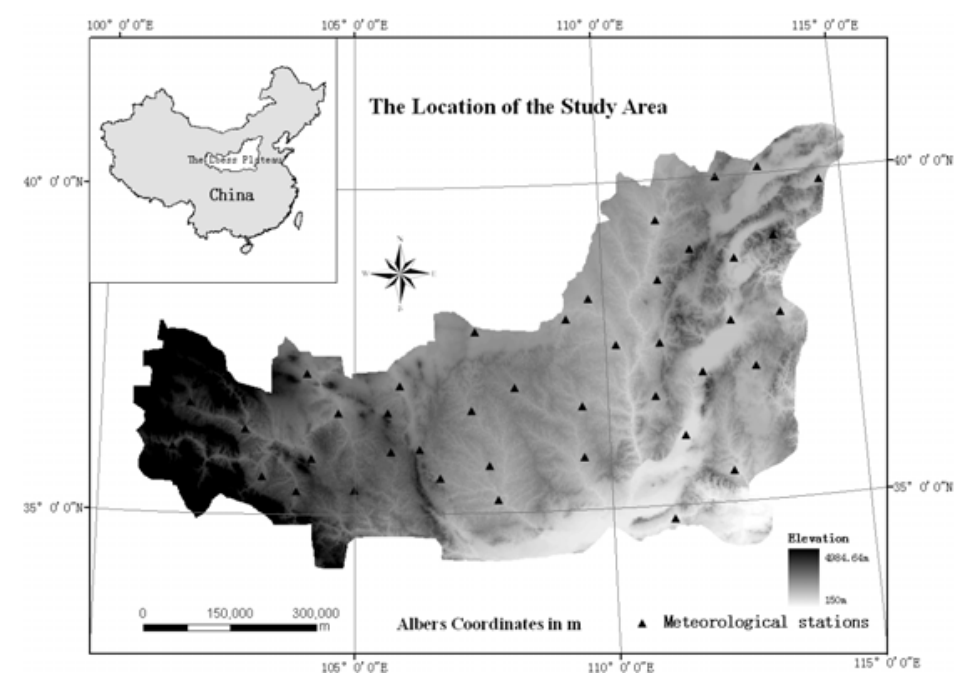

Fig. 1. The location of the Loess Plateau in China. The locations of the Meteorological stations are shown by the black triangle. 


\subsection{Methods}

\subsubsection{Mann-Kendall Method}

The non-parametric Mann-Kendall method was used to assess the significance of a trend, and originated from Mann (1945)[8] and rephrased by Kendall (1948)[9]. The test statistic is calculated as follows:

$$
S=\sum_{i=1}^{n-1} \sum_{j=i+1}^{n} \operatorname{sgn}\left(x_{i}-x_{j}\right) .
$$

Where $n$ is the length of the data set, and $x$ is the data point at time $i$ and $j$, and

$$
\operatorname{sgn}(\theta)=\left\{\begin{array}{cc}
1 & \text { for } \theta>0 \\
0 & \text { for } \theta=0 \\
-1 & \text { for } \theta<0
\end{array}\right.
$$

For independent, identically distributed random variables with on tied data values:

$$
\begin{gathered}
\mathrm{E}(\mathrm{S})=0 . \\
\operatorname{Var}(S)=\frac{n(n-1)(2 n+5)}{18}=\sigma^{2} .
\end{gathered}
$$

When some data values are tied, the correction to $\operatorname{Var}(\mathrm{S})$ is:

$$
\operatorname{Var}(S)=\frac{n(n-1)(2 n+5)-\sum_{i=1}^{n} t_{i}(i)(i-1)(2 i+5)}{18}
$$

Where $t_{i}$ is the number of ties of extent $i$. The standardized test statistic $\mathrm{Z}$ is computed by:

$$
Z= \begin{cases}\frac{S-1}{\sigma} & \text { for } S>0 \\ 0 & \text { for } S=0 \\ \frac{S+1}{\sigma} & \text { for } S<0\end{cases}
$$

The standardized MK statistic Z follows a standard normal distribution with mean of zero and variance of one under the null hypothesis of no trend. A positive $Z$ value indicates an upward trend, whereas a negative one indicates a downward trend. The $p$ 
value (probability value $p$ ) of the MK statistic S of sample data can be estimated using the normal cumulative distribution function:

$$
\mathrm{p}=0.5-\phi(|Z|)
$$

where

$$
\phi(|Z|)=\frac{1}{2 \pi} \int_{0}^{|Z|} e^{-\frac{t^{2}}{2}} d t
$$

If the $p$ value is small enough, the trend is quite unlikely to be caused by random sampling. At the significance level of 0.05 , if $p \leq 0.05$, then the existing trend is assessed to be statistically significant $[10,11]$.

\subsubsection{Sliding $t$-Test Method}

One moment is set to be a reference point in time series " $x$ " with a sample size " $n$ ". The two subsequences before and after the reference point were defined to be $\mathrm{x}_{1}$ and $\mathrm{x}_{2}$.

$$
t=\frac{\bar{X}_{1}-\bar{X}_{2}}{s \cdot \sqrt{\frac{1}{n_{1}}-\frac{1}{n_{2}}}} .
$$

Where

$$
s=\sqrt{\frac{n_{1} s_{1}^{2}+n_{2} s_{2}^{2}}{n_{1}+n_{2}-2}} .
$$

$\mathrm{n}_{1}, \mathrm{n}_{2} \longrightarrow$ the sample size of $\mathrm{x}_{1}$ and $\mathrm{x}_{2}$, separately.

$\bar{X}_{1}, \bar{X}_{2} \longrightarrow$ the average of $\mathrm{x}_{1}$ and $\mathrm{x}_{2}$, separately.

$\mathrm{s}_{1}{ }^{2}, \mathrm{~s}_{2}{ }^{2}$ - the variance of $\mathrm{x}_{1}$ and $\mathrm{x}_{2}$, separately.

If $\left|t_{i}\right|<t_{\alpha}$, there is no significant difference between the two subsequence. Otherwise, there is an abrupt change at the reference point[5].

\section{Results and Discussion}

\subsection{The Spatial Structure of the Precipitation}

The linear regression was used to detect the relationship between the average rainfall for this 50 years and longitude, latitude, elevation (Fig.2). The results presented that the 
average precipitation was linear positively related to the longitude, but it is not significant. The average precipitation was not the linear relation with the latitude or the elevation. It was suggested that the spatial differentiation of the precipitation was not significant on the Loess Plateau from1958 to 2007.
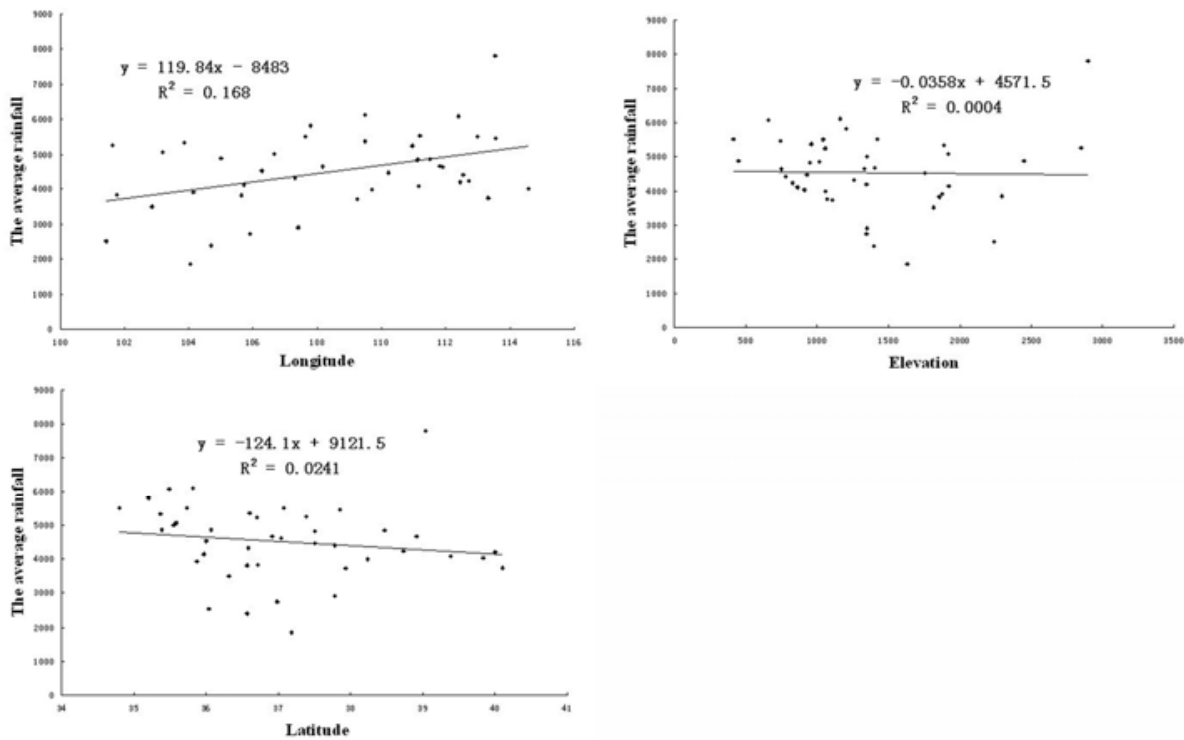

Fig. 2. Relationship between the average rainfall and longitude, latitude, elevation in Loess Plateau, the linear models and $\mathrm{R}^{2}$ also gave in the figure

\subsection{Trend Analysis and Abrupt Changes}

The non-parametric Mann-Kendall method was used to assess the significance of the trend of precipitation. By this method the significant trends were detected for 42 time series of annual precipitation for different stations in the Loess Plateau (Fig. 3).

There were only 7 among 42 stations showed a significant trend $(p=0.05)$, the remaining 35 stations showed no significant trend. Moreover, all these 7 stations with significant trend $(p=0.05)$ displayed a downward trend. The four stations with an upward trend showed in Fig. 3 were not assessed to be statistically significant. In other words, the standardized MK statistic $\mathrm{Z}$ of these four stations is positive, but did not reach significant levels. The standardized MK statistic $Z$ of the remaining 31 stations with no significant trend is negative. It can be easily found from the distribution of the trends for the annual precipitation that no trend and upward trend were mainly in the western portion of Loess Plateau. The downward trend concentrated in the eastern portion of central Loess Plateau. The results also indicated that the precipitation possesses the longitude zonality. This result was similar as Q. Liu et al. [12] that studied the precipitation during 1961-2006 in Yellow River Basin. The precipitation changed 


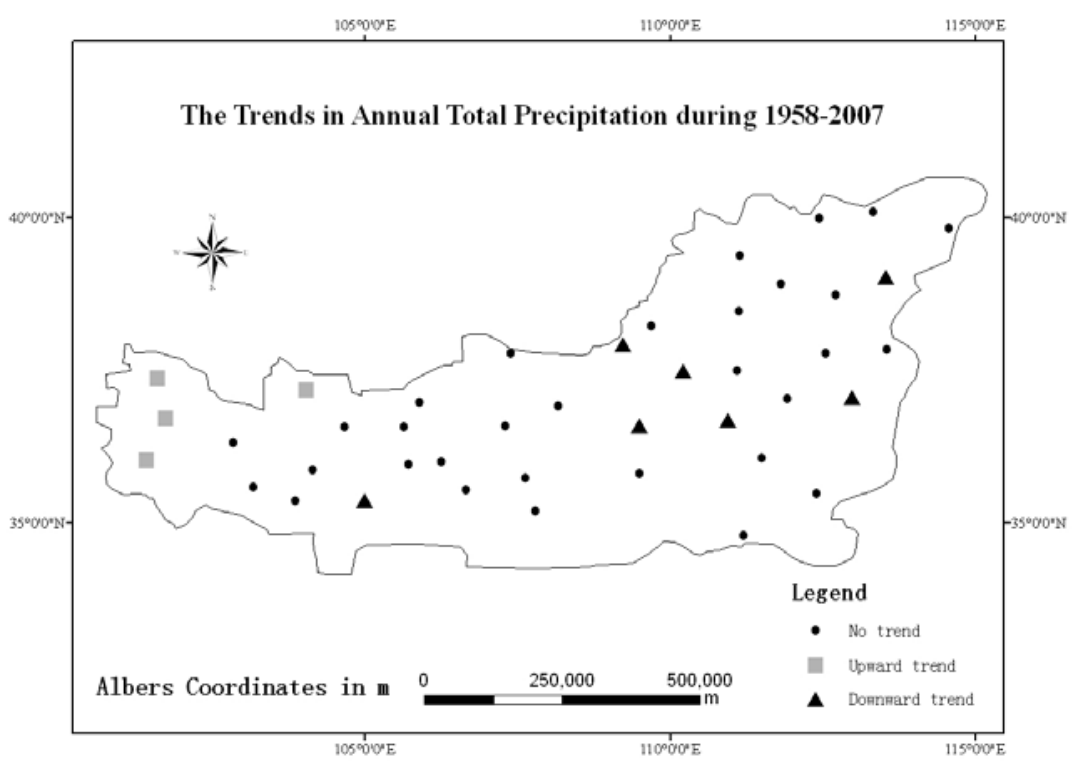

Fig. 3. The trends in annual precipitation during 1958-2007 detected by the Mann-Kendall method in Loess Plateau

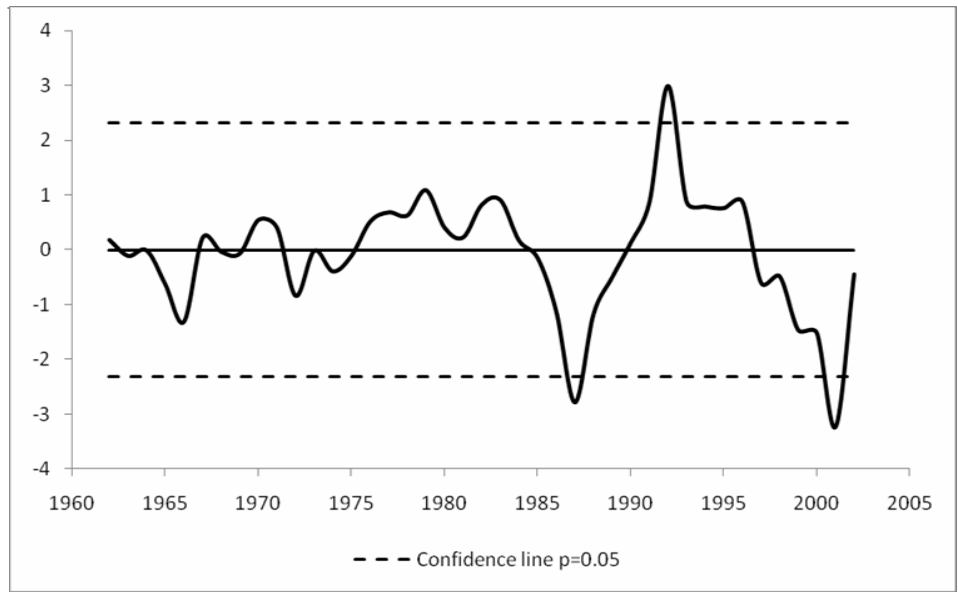

Fig. 4. The abrupt change tested by the Sliding $t$-test for annual precipitation series in Youyu station from 1962 to $2002\left(n_{1}=n_{2}=5\right)$

obviously from west to northeast. This situation may be due to the monsoon, as the precipitation was sensitive to the climatic change. And the influenced by human activities might another reason.

The Sliding $t$-test method was used to test the abrupt changes. The Youyu station $\left(112^{\circ} 27^{\prime} \mathrm{E}, 40^{\circ} 00^{\prime} \mathrm{N}\right)$ was selected as an example to demonstrate the abrupt change 
happening in the time series of annual precipitation $\left(\mathrm{n}_{1}=\mathrm{n}_{2}=5\right)$. It revealed that the abrupt change occurred in 1987, 1992 and 2001 (Fig.4). The $t$-test in 1987 reached the significant level $\left(t_{i}<-t_{0.05}\right)$ which revealed the abrupt change was from less to more. In $1992, t_{i}>t_{0.05}$, i.e. the abrupt change was from more to less. The situation in 2001 was similar to that in 1987.

Because the choice of $\mathrm{n}_{1}$ and $\mathrm{n}_{2}$ are man-made, the results may drift. In order to avoid this situation, the $\mathrm{n}$ should be chose combined with specific needs, and constantly changes, so as to enhance the reliability of the results. The $\mathrm{n}_{1}=\mathrm{n}_{2}=5, \mathrm{n}_{1}=\mathrm{n}_{2}=7, \mathrm{n}_{1}=\mathrm{n}_{2}=10$, $\mathrm{n}_{1}=\mathrm{n}_{2}=11$ and $\mathrm{n}_{1}=\mathrm{n}_{2}=12$ were chose in the study (Tab.1). By comparing, $\mathrm{n}_{1}=\mathrm{n}_{2}=10$ had been chose to analyze abrupt change. The time and frequency of the abrupt changes showed in Fig.5. There were 31 abrupt changes happening in 18 meteorological stations. Two abrupt changes took place in the fallowing 5 stations, Minhe (1979-decreasing change, 1991-increasing change), Huajialing (1985-decreasing change, 1986-decreasing change), Huanxian (1968-decreasing change, 1970-decreasing change), Suide (1995decreasing change, 1996-decreasing change), Lishi (1967-decreasing change, 1990decreasing change). Three abrupt changes took place in Xiji (1967-decreasing change, 1968-decreasing change, 1992-decreasing change). Four abrupt changes took place in the fallowing 2 stations, Jiexiu (1989, 1990, 1991 and 1992-decreasing change), Wutaishan (1988, 1989, 1992 and 1996-decreasing change). 12 stations among these 18 stations locate in the northeast of Loess Plateau. 20 times of the 31 abrupt changes occurred in the northeast. All of this indicated that the northeast of Loess Plateau was sensitive to the climate change.

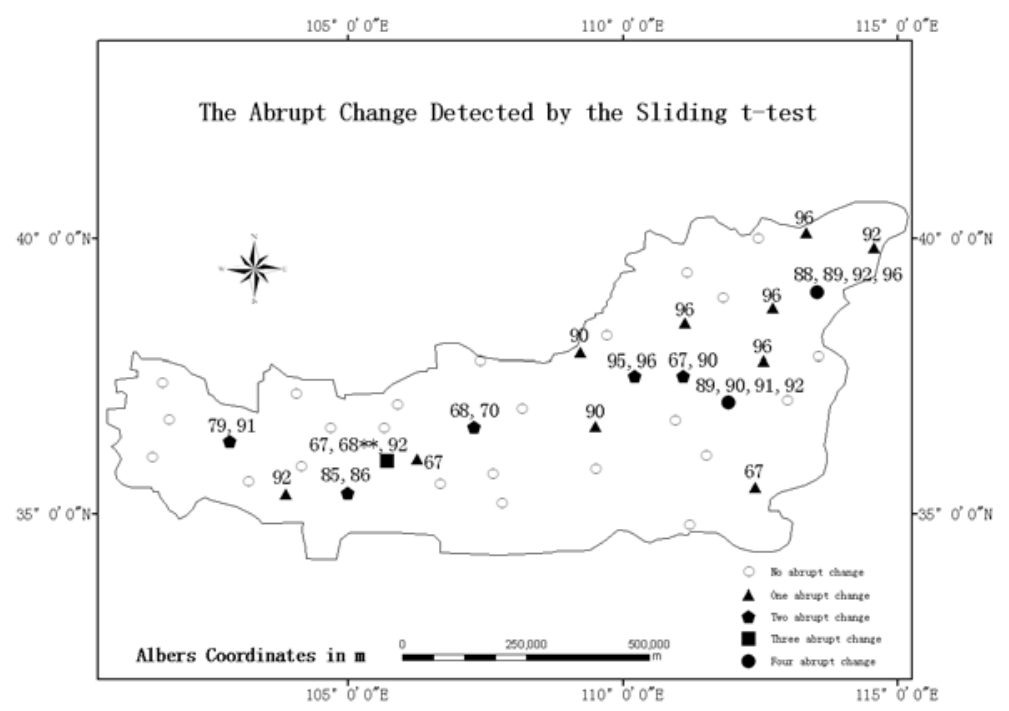

Fig. 5. The time and frequency of the abrupt change detected by the Sliding $t$-test $(n 1=n 2=10)$ in the meteorological stations of Loess Plateau. The year that the abrupt change happened has been simplified in two figures, e.g., 67 for 1967; ** indicated $p<0.01$. 


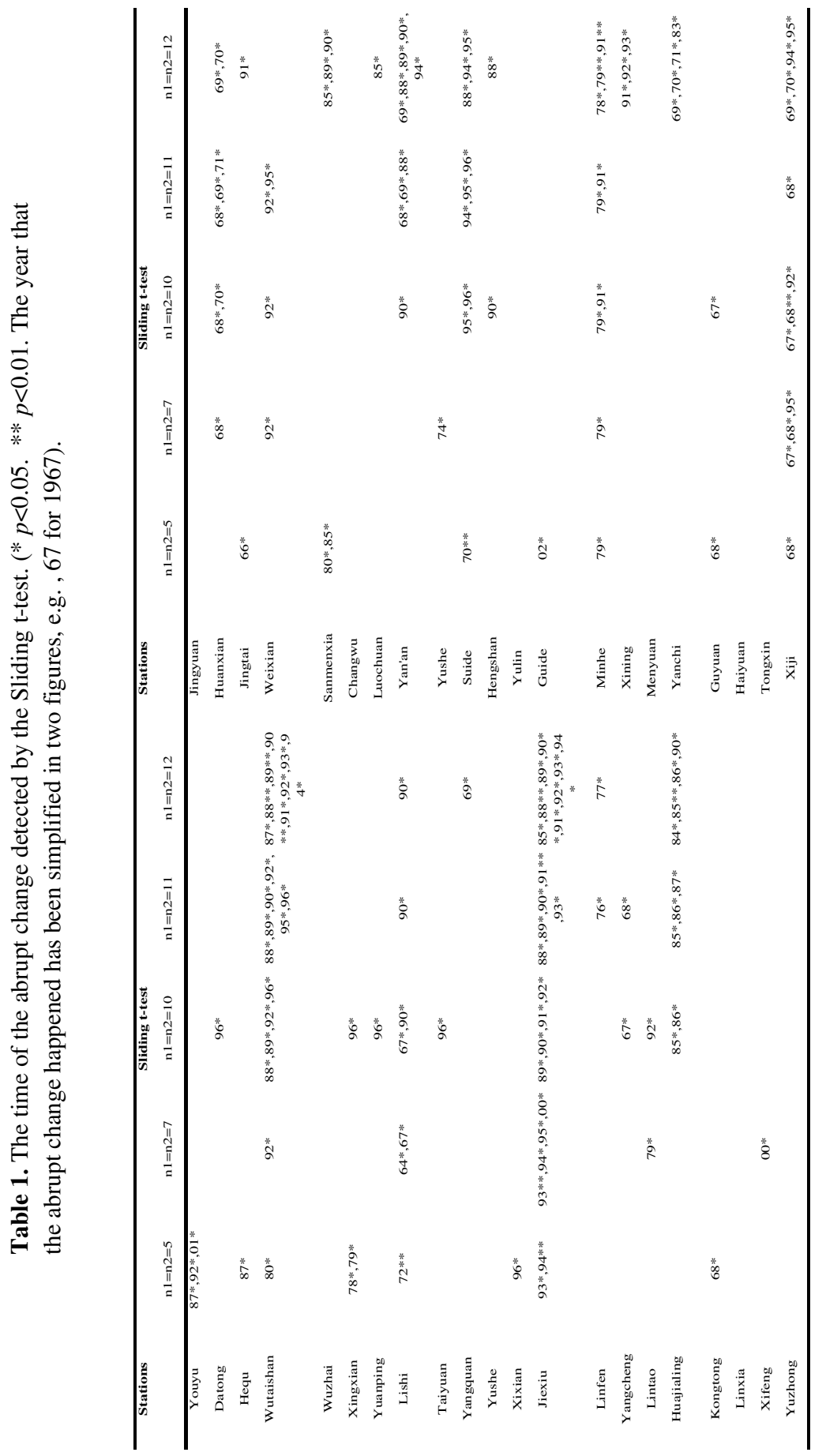




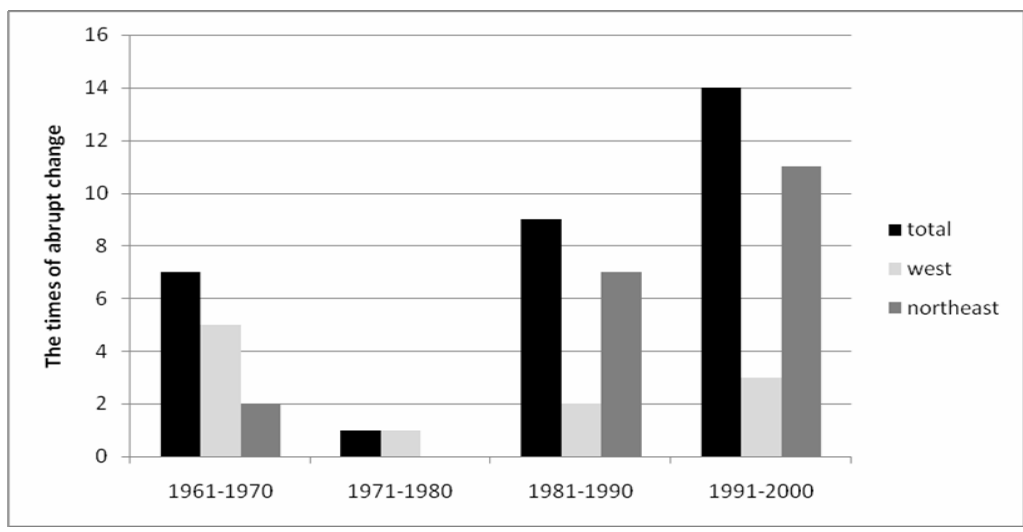

Fig. 6. The times of abrupt change detected by the Sliding $t$-test $\left(n_{1}=n_{2}=10\right)$ in different decades

Moreover, the times of abrupt changes happened in different decades showed in Fig.6. It can be found from the chart that the times of abrupt change increase with the time except from 1971 to 1980 . Only one station which located in the west of Loess Plateau happened abrupt change from 1971 to 1980 . The abrupt change mainly happened in west of Loess Plateau from 1961 to 1970. However, during 1981-1990 and 1991-2000, the abrupt change was mainly happened in the northwest of Loess Plateau. That is the abrupt changes happened in the northeast portion of the Loess Plateau were relatively later than those in the west portion of the Loess Plateau. Moreover, there were 6 stations among 12 which locate in the northeast happened abrupt change in 1996. It indicated that the northeast of Loess Plateau became more and more sensitive to the climate change since 1980s. The reasons that affected the precipitation in the Loess Plateau need further study on the interaction between the climate change and human activities. The results in this study are significance for the further studies and forecast of climate in Loess Plateau, and also offer the basis for decision-makers.

\section{Conclusions}

In this study, the Mann-Kendall method and Sliding $t$-test were used to analyze the precipitation from 1958 to 2007 in Loess Plateau. The results presented as follows:

(1) The relationship between precipitation and longitude/latitude/elevation is not linear. The precipitation didn't have clear trend with the longitude/ latitude/elevation increasing.

(2) The results of Mann-Kendall method indicated that only 7 stations showed a significant trend, the other 35 stations have no significant trend. Only 4 stations have positive $\mathrm{Z}$ values but didn't reach the $95 \%$ significant level.

(3) The results of Sliding $t$-test showed that there were 31 abrupt changes happening in 18 meteorological stations. Most of the abrupt changes happened in the northeast of Loess Plateau. Moreover, the abrupt changes happened in the northeast 
concentrated during 1980s and 1990s. And the abrupt changes happened in the northeast portion of the Loess Plateau were relatively later than those in the west portion of the Loess Plateau.

(4) The northeast of Loess Plateau was sensitive to climate change recent years, as most of the abrupt changes occurred at here during 1980s and 1990s. More attention should be paid to this region, and the changes in land cover/use could be considered in further studies.

\section{Acknowledgments}

This work is financial supported by National Key Basic Research Program (973) project (2007CB106804) and the Construction of an Information Platform/module in Eco-agricultural Assessment and Management (EAM) (2010DFA31450). The authors are grateful to the anonymous referees for their careful corrections and constructive comments on the manuscript. The authors thank the China Meteorological Data Sharing Service System for offering the precipitation data.

\section{References}

1. Alley, R.B., Marotzke, J., Nordhaus, W.D., et al.: Abrupt climate change. Science 229, 2005-2010 (2003)

2. Yue, S., Pilon, P., Cavadias, G.: Power of the Mann-Kendall and Spearman's rho tests for detecting monotonic trends in hydrological series. Journal of Hydrology 259, 254-271 (2002)

3. Douglas, E.M., Vogel, R.M., Kroll, C.N.: Trends in floods and low flows in the United States: impact of spatial correlation. Journal of Hydrology 240, 90-105 (2000)

4. Birsan, M.V., Molnar, P., Burlamdo, P., Pfaundler, M.: Streamflow trends in Switzerland. Journal of Hydrology 314, 312-329 (2005)

5. Wei, F.: The statistics and prediction of climate. China Meteorological Press (1999) (in Chinese)

6. He Xiubin, L.Z., Hao, M., Tang, K., Zheng, F.: Down-scale analysis for water scarcity in response to soil-water conservation on Loess Plateau of China. Agriculture, Ecosystems and Environment 94, 355-361 (2003)

7. Jie We, J.Z., Tian, J., He, X., Tang, K.: Decoupling soil erosion and human activities on the Chinese Loess Plateau in the 20th century. Catena 68, 10-15 (2006)

8. Mann, H.B.: Non-parametric test against trend. Econometrika 13, 245-259 (1945)

9. Kendall, M.G.: Rank Correlation Methods. Hafner, New York (1948)

10. Douglas, E.M., Vogel, R.M., Kroll, C.N.: Trends in floods and low flows in the United States: impact of spatial correlation. Journal of Hydrology 240, 90-105 (2000)

11. Bouza-Deaño, R., Ternero-Rodríguez, M., Fernández-Espinosa, A.J.: Trend study and assessment of surface water quality in the Ebro River (Spain). Journal of Hydrology 361, 227-239 (2008)

12. Liu, Q., Yang, Z.F., Cui, B.S.: Spatial and temporal variability of annual precipitation during 1961-2006 in Yellow River Basin, China. Journal of Hydrology 361, 330-338 (2008) 